\title{
RELATIONSHIPS AMONG TEACHER COMMUNICATION STYLE, TRAIT AND STATE COMMUNICATION APPREHENSION AND TEACHER EFFECTIVENESS
}

\author{
PATRICIA KEARNEY \\ California State University- \\ Sacramento
}

\author{
JAMES C. MCCROSKEY \\ West Virginia University
}

\begin{abstract}
The empirical model tested in this study examined the effects of teacher communication style (TCS) on students ${ }^{\circ}$ affect and behavioral commitment in college classes. Additionally, the model posited a mediational function for teachers' and students ${ }^{\circ}$ trait and state communication apprehension for perceptions of teacher style and teacher effectiveness. Multiple regression and commonality analyses indicated that only student perceptions of all three dimensions of TCS were related to teacher effectiveness. Students who perceived teachers as highly versatile and responsive also reported lower fears about communicating in class-regardless of students' trait communication apprehension level.
\end{abstract}

Granted: effective teaching requires competent knowledge of subject matter. Yet, instructional technologists define teaching as more than information dissemination from a central source (Vargas. 1977; Wittich \& Schuller, 1973; Skinner, 1968; Corey, 1967). Nevertheless, teacher credentials traditionally emphasize content competencies to the exclusion of competencies applicable to the relational teacher-student communicativeexchange process. The impact of such neglect is shown in students' perceptions of their own negative experiences with teachers. Branan (1972) discovered that teachers were targeted as the largest role group who negatively impacted students' lives. Students reported situations with teachers that involved "humiliation in front of a class, unfairness in evaluation, destroying self-confidence, personality conflicts, and embarrassment'" (p. 82).

To suggest that teaching involves effective relating as well (Combs, 1959), requires the identification of teacher communicative behaviors or students' perceptions of teacher characteristics that serve to enhance learning. This study seeks to isolate variables impacting teacher effectiveness. That is, what communicative behaviors idiosyncratic to a teacher's style of presentation produce positive student affective orientations and behavioral commitment toward the course, instructor, and content area'? Further, what is the nature of the relationship between teachers' and students' trait and : communication apprehension (CA) on stude perceptions of their teachers' communicative haviors in the classroom and teacher effectiven

An effective teacher, as operationalized in study, is one who elicits positive orientations $t$ students. The criterion of affective learning comes is critical to the entire learning process. relates to increased student involvement commitment to learning (Andersen, 1979b; El 1979; Keller \& Sherman, 1974; Wittich \& Schu 1973; and Bruner, Goodnow \& Austin, 19 Promoting positive attitudes toward learning $n$ indeed, be the primary role of teachers in classroom-learning environment. Engenderir. "love-for-learning" orientation may enable n generalized approach orientations toward lear both within and outside the classroom (cf, S becker, 1974; Furth, 1969; and Ginsburg \& Op 1969).

\section{TEACHER COMMUNICATION STYLE}

Teacher communication style (TCS) refers tc collective perceptions of others and/or s perceptions of a teacher's relational image in classroom (Kearney-Knutson, 1980). While : lated instrument. communicator style, has 1 used to assess such perceptions of teachers (Nol 
1977), the CS construct is not based on instructional communication theory. Similarly, social style (Merrill, 1974; Buchholz, Lashbrook \& Wenburg, 1975), designed for organizational contexts, does not focus on behaviors specifically relevant to teachers in classroom environments.

Yet the construct of social style does identify basic dimensions that are particularly relevant to instructors-assertiveness, versatility, and responsiveness. Assertiveness refers to perceptions of teacher control in the classroom. Such control may be demonstrated by the teacher's ability to maintain students' selective attention toward instruction, to promote desirable learning environments, and to ensure student activity and productivity. Relying on the instructional literature, effective teachers are those who serve as controllers and who provide structure in the classroom (Deshpande, Webb, \& Marks, 1970). Effective teachers are initiators; they exude self-confidence, and they direct classroom discussion (Ryans, 1960). They engage student attention through dynamic delivery, vocal variety, and frequent gestures and movement (Wyckoff, 1973).

Versatility, the second dimension of teacher style, refers to perceived adaptiveness of the instructor to the needs and characteristics of students. Highly versatile teachers are those who adapt to the communicative behaviors of their students. Adapting to individual needs or learning histories and entry levels are espoused as requisites for many instructional paradigms (Vargas, 1977; Holland et al. 1976; Keller \& Sherman, 1974; Davies, 1973; Wittich \& Schuller, 1973; Kemp, 1971; Furth, 1969). Such technologies of teaching recognize the student as an individualized learner who requires the teacher to accomodate appropriately.

Teaching styles that are indicative of high responsiveness are characterized as emotional, sensitive, social, understanding, and approachable. The Keller Plan or Personalized System of Instruction (Keller \& Sherman, 1974) incorporates strategies for emitting positive feedback, supplying rewards, and minimizing frustration or failure for the students. Rogers (1969) asserts that teachers should openly express their own feelings and accept feelings from students. Empirically, students' perceptions of instructors' immediacy or psychological closeness have been found to be significant pre- dictors of affective learning and behavioral commitment (Andersen, 1979b).

Effective teachers, as suggested by the instructional communication literature. are those who are perceived as highly assertive. versatile, and responsive. From a relational perspective, it is interesting to note both the way in which a teacher views himself as a communicator in the classroom and the ways in which students perceive the teaching style of the communicator in that same environment. While Norton (1977) found that college teachers and their students viewed the communicator style (CS) of the teacher similarly, Kearney-Knutson (1980) was unable to obtain definitive consensual perceptions between teachers and students for TCS. If, as this literature review indicates, assertiveness, versatility , and responsiveness are predictive of teaching effectiveness, is it teacher perceptions of their own TCS or student perceptions of it that provide the most meaningful predictor? (The overall a priori empirical model is presented progressively in five stages and reported in " Results".)

\section{PERCEPTIONS OF TCS MEDIATED AS A FUNCTION OF COMMUNICATION APPREHENSION}

If consensus between self and others' perceptions of TS is not indicated, a teacher's or student's own state or trait level of communication apprehension may impact such consistency. Trait CA is conceptualized as high fear or anxiety about potential or actual oral communication encounters (McCroskey, 1977). Such apprehension generally takes the form of approach or avoidance behaviors across a variety of communication situations.

In contrast to generalized apprehension toward all communication encounters, state CA refers to anxieties in particular oral communication situations (Spielberger, 1966; Lamb, 1972; McCroskey, 1977; Richmond, 1978). Traditionally, state $\mathrm{CA}$ has been referred to as stage fright that is associated with public-speaking situations (McCroskey, 1977). That is, most people experience a condition of high-state CA when confronted with public presentations. However, state $\mathrm{CA}$ also can occur as a function of dyadic interactions during the acquaintance process (Richmond, 1978). Such state 
communicative anxiety can result during normal communication encounters with a specific target individual.

Teachers in classroom environments may experience trait as well as state (i.e., when communicating with students in a particular class) communicative anxiety levels that in turn may affect their own perceptions of their teacher style. High-CA teachers may engage in avoidance behaviors that result in perceptions of less assertiveness, responsiveness. and versatility. Conversely, low state and/or trait apprehensives may perceive themselves as more assertive, responsive. and versatile, as is evidenced by more approach behaviors that are associated with those dimensions of TCS.

Students' CA (trait or teacher-specific state) may mediate perceptions of the teacher's style as well. Andersen (1979a) reported differential perceptions of another's communicator style as a function of the perceiver's own communicative anxiety. High-CA students perceived their teachers as less animated, impression-leaving, dramatic, friendly, and open than students low in trait CA. Further, high-CA students perceived their teacher as less immediate or less affiliative in their classroom interactions.

Teacher's level of trait CA may also impact students' perceptions of the instructors' communicative behaviors. (See McCroskey, 1977 for a review of the literature addressing others' perceptions toward CA's). Trait and/or state anxiety associated with teaching in a particular.classroom environment may produce differential communicative behaviors that are perceived by students as higher or lower in assertiveness, responsiveness, and versatility of a particular teacher style. Richmond (1978) found that for interpersonal perceptions in dyads, individuals' state level of CA was a much more powerful predictor than trait levels of CA. Given such perceptual indices as a function of another's CA level (state and/or trait), it is plausible that teachers exhibiting behaviors indicative of levels of $\mathrm{CA}$ will be perceived differentially.

It appears, then, that teacher and student perceptions of TCS may be mediated by both the teacher's level of trait and state CA and the student's trait and state CA. While it is posited in this research that highly assertive, responsive, and versatile teacher styles will be evaluated as more effective teachers. not all students may perceive teacher styles simi- larly. If a teacher's style is perceived as a function of $\mathrm{CA}$, differential affective learning outcomes may result.

\section{COMMUNICATION APPREHENSION AND TEACHER EFFECTIVENESS}

While CA has failed to be a meaningful predictor of cognitive achievement (Davies \& Scott, 1978; Scott \& Wheeless, 1978), trait CA has proved to be highly associated with student affective learning. Scott \& Wheeless (1978) provide a critical review and assessment of this relationship. These authors conclude that trait $\mathrm{CA}$ is negatively associated with students' generalized attitudes toward school (Hurt \& Preiss. 1978); instructional strategies that require oral communication (Scott, Yates, \& Wheeless, 1975); and instructional environments that optimize potential for interaction (McCroskey \& Andersen, 1976). Additionally, teachers perceive students differentially as a function of student levels of CA. McCroskey \& Daly (1976) and Smythe \& Powers (1978) reported a negative expectancy effect involved in teachers' assessments of the high-CA student.

A corresponding relationship between state $\mathrm{CA}$ and affective learning has yet to be determined. Oral communicative anxieties evidenced in a particular classroom (i.e., situation-specific) should produce similar teacher expectancies and student affective learning. That is, students high in state CA should engage in the same avoidance behaviors reported for the high trait CA's-at least, for that particular environment.

This study will examine ways in which the teacher can enhance his effectiveness for students with varying levels of communication apprehension, as a function of TCS. Further, differential perceptions based on trait or state CA toward teacher communicative behaviors in the classroom will be empirically investigated.

\section{METHOD}

\section{Subjects}

The subject pool consisted of experienced college teachers and their students during the 1978 fall semester at California State University at Sac- 
ramento. College teachers from numerous and diverse departments (e.g.. physical education, business, communication studies, foreign languages, etc.) were selected to increase the likelihood of a wide range of teacher styles. Classes were chosen that reflected a traditional instructional format with class size ranging from $10-45$ students (ave. class size $=15.46)$. Over 300 college teachers were interviewed and asked to participate. Approximately one-half agreed, while 96 actually completed the study. The student sample consisted of a total of 1484 individuals.

\section{Procedures}

Both teachers and students completed an initial self-report instrument that measured trait $\mathrm{CA}$ at the beginning of the semester. Approximately six weeks later, the same teachers and students completed two questionnaires at the beginning of a regular class period. These instruments measured state CA and TCS. At the end of that same class period, student affect and behavioral commitment were assessed through students' self-report measures. Subjects were told that the purpose of data collection was to learn more about teaching in the college classroom. All responses were confidential and anonymous.

\section{Measuring Instruments}

Teacher Communication Style. TCS was measured by a 36 -item Likert-type instrument developed by Kearney-Knutson (1980). The TCS instrument was administered to teachers with directions that indicated a self-report assessment of their communication behaviors with students "in this particular class." While the students were given the same measure, their instructions required an assessment of their teacher's communicative behaviors " in this particular class." Split-half reliability estimates for assertiveness were .84 for the teacher sample and .85 for students. Versatility yielded .74 for teachers and .89 for students, while responsiveness yielded .85 for teachers and .89 for students. Measures of skewness and kurtosis indicated that all scores were normally distributed for both teacher and student samples, except for teachers' self-reported asser- tiveness (skewness $=-.87$; kurtosis $=1.45$ ) .

Trait Communication Apprehension. Communication apprehension (trait) was measured by the 25 item, Likert-type instrument developed by McCroskey (1970). Split-half reliability estimates for student Personal Report of Communication Apprehension (PRCA) was .93 and .91 for the teacher PRCA. Measures for skewness and kurtosis indicated that for the teacher sample a leptokurtic distribution for teacher PRCA scores was indicated (skewness $=.86$; kurtosis $=1.48)$. More importantly, when compared to the student sample of PRCA scores $(\bar{X}=69.34)$, the mean for the teacher sample $(\bar{X}=54.95)$ was considerably lower. Consequently, the teacher sample was comprised of predominantly moderate to low apprehensive teachers. While one may conclude that perhaps the college-teaching profession includes moderate to low CA's, a better interpretation based on this particular research design was that primarily moderate to low apprehensives chose to participate in this evaluative project. High CA's may, instead, have chosen not to participate because of an unwillingness to have their communication behaviors evaluated by others.

State Communication Apprehension. State CA was measured by the 20 -item state version of the StateTrait Anxiety Inventory (A-State) that was developed by Spielberger (1966) and modified by Richmond (1978). For purposes of this study, the A-State instrument was adapted to anxieties associated with interactions with "this particular instructor in this class most of the time" (student version), or interactions associated with this particular class (teacher version). Teachers in this sample were comprised of predominantly moderate to low state apprehensives in the classroom (skewness = 1.31 , kurtosis $=1.64$ ). Scores for students' state $\mathrm{CA}$ indicated a normal distribution.

Affect and Behaviorál Commitment. Affect consisted of student attitudes toward behaviors recommended in the course, content or subject matter, and the instructor. Each specified affect was followed by four semantic-differential-type scales. Students' behavioral commitment toward behaviors 
recommended in the course and the likelihood of enrolling in a similar class were additionally assessed as indicants of teaching effectiveness. Again, these items were followed by four semanticdifferential-type scales. Both scales have been used repeatedly in communication research to measure teacher effectiveness (cf. Andersen. 1978b; Scott. Yates, \& Wheeless, 1975).

Factor analysis of all affect and behavioral commitment measures, employing an oblique rotation and forcing five factors, resulted in an interpretable five-factor solution. For the five-factor solution. items in each set of scales had their primary loadings on the intended factors. A two-factor solution (with oblique rotation) indicated an affective factor and a behavioral commitment factor, with an inter-factor correlation of .63. The single-factor, unrotated solution had all items with their primary loadings on the first factor (these tables are available from the authors upon request). A parsimonious interpretation of the affect and behavioral commitment measures indicated a single-factor solution. Consequently, the criterion measures of affect and behavioral commitment were treated as a single factor for hypothesis testing.

The analyses reported here include a teacher sample of 96 subjects and a student sample of 1484 . While preliminary analyses were based on the entire student sample (i.e., means, standard deviations, factor structures, reliability estimates, etc.), mean student responses in individual classes for every measure were used for tests of hypotheses. This procedure reduced an inflated N-size of 1484 to 96 . As a result, teacher and student class effects could be represented best for interpretable results.

All tests for significance were set at alpha level .05. A priori statistical power for all correlation analyses was .85 , assuming a medium-effect criterion. Employing the same medium-effect criterion, a priori statistical power for two, three, four, and five variable multiple-regression analyses were .92 , $.89, .86$, and .84 , respectively (Cohen, 1977). Finally, tests for nonlinearity indicated all relationships were linear.

\section{TEST OF HYPOTHESES: RESULTS}

Each successive stage of the empirical model, hypotheses, and research questions are outlined below with appropriate statistical analyses delineated.

\section{FIGURE 1}

TCS $_{t} \longrightarrow$ Affect and Behavioral Commitment

Step 1:

$\mathrm{H}_{1}$ : Teachers' self-reported communication style is positively correlated with students ' affect \& behavioral commitment.

$\mathrm{H}_{\mathrm{la}}$ : Teachers' perceptions of their own as. sertiveness are positively correlated with students' affect and behavioral commitment.

$\mathrm{H}_{\mathrm{lb}}$ : Teachers' perceptions of their own versatility are positively correlated with students' affect and behavioral commitment.

$\mathrm{H}_{\mathrm{lc}}$ : Teachers' perceptions of their own responsiveness are positively correlated with students' affect and behavioral commitment.

Hypothesis I was tested by a multiple-regression analysis with teachers' perceived assertiveness, versatility, and responsiveness as the three predictors, and affect and behavioral commitment as the single criterion. Hypothesis 1 failed to receive confirmation at the .05 level $(F=1.18$; nsd $)$. Simple correlations between teachers' assertiveness $(r=.08$; nsd $)$, versatility $(r=.04$; nsd $)$, and responsiveness ( $r=.04$; nsd), with students' affect and behavioral commitment further demonstrated the conclusion that Hypothesis 1 failed to be confirmed.

Because teacher and student perceptions of teacher communication style were determined to be separate variables for the same data sets (KearneyKnutson, 1980), the next analyses were based on students' perceptions of the teachers' communication styles.

\section{FIGURE 2}

TCS $_{\mathrm{S}} \longrightarrow$ Affect and Behavioral Commitment

$\mathrm{H}_{2.2}$ : Students' perceptions of teacher communication style are positively correlated with students' affect and behavioral commitment. 
$\mathrm{H}_{2 \mathrm{a}}$ : Students perceptions of their teacher's assertiveness are positively correlated with students' affect and behavioral commitment.

$\mathrm{H}_{2 \mathrm{~b}}$ : Students' perceptions of their teacher's versatility are positively correlated with students' affect and behavioral commitment.

$\mathrm{H}_{2 \mathrm{c}}$ : Students' perceptions of their teacher's responsiveness are positively correlated with students' affect and behavioral commitment.

Hypothesis 2 was tested by a multiple regression analysis with students' perceptions of their teacher's assertiveness, versatility, and responsiveness as predictors and students' affect and behavioral commitment as the criterion. Hypothesis 2 was supported. Students' perceptions of TCS accounted for 38 percent of the variance in students' affect and behavioral commitment $(F=18.62 ; p<.0001)$. Commonality analysis was employed to decompose $R^{2}$ ( $R^{2}$ for assertiveness, versatility, and responsiveness $=.3778$ ) into its unique and common components of predictor variables (Siebold \& McPhee, 1979; McPhee \& Siebold, 1979). This analysis indicated that while unique variance was attributable to each variable (assertiveness $=.0416$; versatility $=.0283$; and responsiveness $=.0050$ ), combinations of variables contributed substantially more explained variance in the criterion. The primary predictors were combinations of responsiveness and versatility (.1193) and all three predictors (.1457). Summary Table 1 provides these results.

Consequently, Hypotheses $2 \mathrm{a}, 2 \mathrm{~b}$, and $2 \mathrm{c}$ were supported with the interpretation that all three variables in combination were meaningful predictors of students' affect and behavioral commitment.

\section{FIGURE 3}

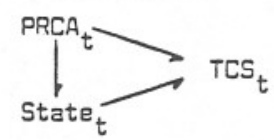

Step 2:

$\mathrm{H}_{3}$ : A linear combination of teachers' trait $\left(\right.$ PRCA $\left._{t}\right)$ and state $\left(\right.$ State $\left._{t}\right)$ communication apprehension significantly predicts each of the following three dimensions of teachers self-reported communication style $\left(\mathrm{TCS}_{1}\right)$ :

$\mathrm{H}_{3 \mathrm{a}}$ : Assertiveness

$\mathrm{H}_{3 \mathrm{~b}}$ : Versatility

$\mathrm{H}_{3 \mathrm{c}}$ : Responsiveness

To test Hypothesis 3, a series of three multiple regression analyses were employed with teachers' trait and state CA as predictors and teachers' selfreported assertiveness, versatility, and responsiveness as three independent criterion variables. Results indicated confirmation of Hypotheses 3a, 3b. and $3 \mathrm{c}$. Teachers' trait and state CA explained 27 percent of the variance for assertiveness $(F=17.22$; $\mathrm{p}<.0001) ; 15$ percent of the variance for versatility $(\mathrm{F}=8.23, \mathrm{p}<.0008)$; and 16 percent of the variance for responsiveness $(\mathrm{F}=9.28, \mathrm{p}<.0004)$. Pearson $r$ correlations indicated that teachers' PRCA (trait) was significantly correlated with teachers self-reported assertiveness $(-.46, \mathrm{p}<$ $.0001)$, versatility $(-.20, \mathrm{p}<.05)$, and responsiveness $(-.31, \mathrm{p}<.01)$. Teachers' state CA was significantly correlated with teachers' assertiveness $(-.43, \mathrm{p}<.0001)$, as well. However, it is important to note that teachers' PRCA was significantly correlated with teachers' state CA $(.46 ; p<.0001)$. Decomposition of predictable variance unique and common to PRCA and state apprehension enabled a more precise estimate of the contribution of each predictor.

Commonality analysis determined that for assertiveness $\left(R^{2}=.2702\right)$, teachers' trait CA explained 8.71 percent of the variance and state $C A$ explained 6.03 percent of the total variance. PRCA and state CA jointly accounted for 12.28 percent of the variance in assertiveness. The best interpretation for total variance explained in assertiveness, then, was the combined predictors of teachers' trait and state communication apprehension.

As for versatility, variance unique to teachers' PRCA was .06 percent while state apprehension contributed 11.07 percent unique variance (total $\mathrm{R}^{2}=.1504$ ). Combined trait and state measures yielded an additional 3.91 percent explained variance. Teachers' state apprehension, then, was the best predictor of total explained variance for versatility.

Finally, commonality analysis demonstrated that for teachers' self-reported responsiveness, variance 
TABLE 1

Commonality Analysis Summary Table

Perceived Teacher Style as Predictor of Students'

Affect and Behavioral Commitment

\begin{tabular}{|c|c|c|c|}
\hline \multirow{2}{*}{ Unique \& Common Effects } & \multicolumn{3}{|c|}{$\begin{array}{c}\text { Components in Perceived } \\
\text { Teacher Style }\end{array}$} \\
\hline & $\begin{array}{l}\text { Assert- } \\
\text { iveness }\end{array}$ & $\begin{array}{l}\text { Versa- } \\
\text { tility }\end{array}$ & $\begin{array}{l}\text { Respon- } \\
\text { sivenes }\end{array}$ \\
\hline Unique to Assertiveness & .0416 & & \\
\hline Unique to Versatility & & .0283 & \\
\hline Unique to Responsiveness & - & & .0050 \\
\hline $\begin{array}{c}\text { Common to Assertiveness } \\
\text { and Versatility }\end{array}$ & -.0168 & -.0618 & \\
\hline $\begin{array}{c}\text { Common to Assertiveness } \\
\text { and Responsiveness }\end{array}$ & .0547 & & .0547 \\
\hline $\begin{array}{l}\text { Common to Versatility } \\
\text { and Responsiveness }\end{array}$ & & .1193 & .1193 \\
\hline $\begin{array}{c}\text { Common to Assertiveness, } \\
\text { Versatility and } \\
\text { Responsiveness }\end{array}$ & .1457 & .1457 & .1457 \\
\hline Totals & .2252 & .2765 & .3247 \\
\hline Squared Multiple Correlation: .3778 & & & \\
\hline
\end{tabular}

unique to teachers' PRCA was 2.21 percent; variance unique to teachers' state apprehension was 7.28 percent; and common to teachers' PRCA and state was 7.14 percent (total $\mathrm{R}^{2}=.1663$ ). Consequently, for teachers' self-reported responsiveness, state CA was the best predictor of total explained variance.

The next analyses were based on students' perceptions of their teachers' communication style as predicted by their teachers' trait and state CA.

FIGURE 4

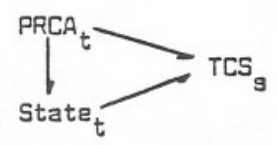

$\mathrm{H}_{4}$ : A linear combination of teachers' trait and state CA significantly predicts each of the following dimensions of students' perceptions of teacher communication style $\left(\mathrm{TCS}_{\mathrm{s}}\right)$ :

$\mathrm{H}_{4 \mathrm{a}}$ : Assertiveness

$\mathrm{H}_{4 \mathrm{~b}}$ : Versatility

$\mathrm{H}_{4 \mathrm{c}}$ : Responsiveness

To test for Hypothesis 4 (a, b, and c), a canonical correlation analysis was employed with teachers' PRCA and state CA as the predictor set and students' perceptions of TCS (i.e., assertiveness, versatility, and responsiveness) as the criterion set. Results were nonsignificant at the .05 level. A more precise test of the relationship between teacher's 
communication apprehension and students' perceptions of each of the three dimensions of TCS involved a series of three multiple regression analyses. Teachers' trait and state CA served as predictors with assertiveness, versatility, and responsiveness as separate criterion variables. Multiple regression analysis showed that for students' perceptions of assertiveness, teachers' PRCA was a significant predictor of the sequentials $(F=7.59$; $\mathrm{p}<.05)$, while state was not $(\mathrm{F}=1.42$, nsd $)$. For versatility and responsiveness, neither teachers' PRCA nor state CA was a significant predictor.

FIGURE 5

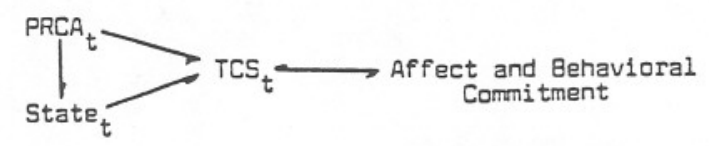

Step 3:

Research question 1: Will the addition of teachers' state and trait apprehension be more predictive than teachers' self-reported teacher communication style $\left(\mathrm{TCS}_{\mathrm{t}}\right)$ alone in explaining students' affect and behavioral commitment?

Multiple-regression analysis was employed to answer Research Question 1 with teachers' PRCA, state, assertiveness, versatility, and responsiveness comprising the predictor set and students' affect and behavioral commitment as the single criterion variable. Nonsignificant results were obtained $(F=.53$; nsd). The next analysis was based on students' perceptions of TCS.

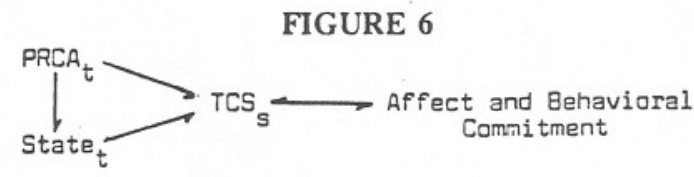

Research question 2: Will the addition of teachers' PRCA and state apprehension be more predictive than students' perceptions of teacher communication style $\left(\mathrm{TCS}_{\mathrm{s}}\right)$ alone in explaining students' affect and behavioral commitment?

Research Question 2 was answered by multiple-regression analysis with teachers' PRCA and state CA as well as students' perceptions of teacher assertiveness, versatility, and responsiveness as predictors and students' affect and behav- ioral commitment as the single criterion variable. Results indicated a significant relationship ( $\mathrm{F}=$ $11.23, \mathrm{p}<.0001)$. However, partial-regression analysis demonstrated that only students' perceptions of teacher assertiveness significantly predicted students' affect and behavioral commitment ( $\mathrm{F}=$ $6.33, \mathrm{p}<.01$ ). Additionally, total explained variance was not increased with the addition of teachers' trait and state CA ( $\mathrm{R}^{2}=.382$ in both analyses). In response to Research Question 2, the addition of teachers' PRCA and state apprehension failed to be more predictive than students' perceptions of TCS alone in explaining students' affect and behavioral commitment.

\section{FIGURE 7}

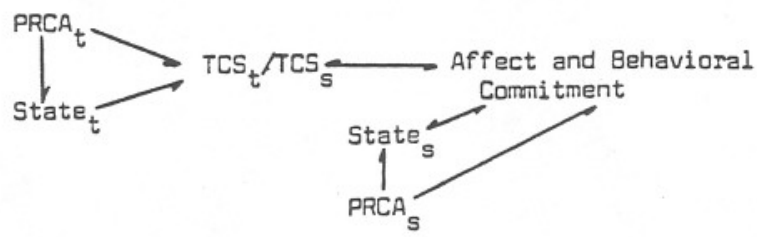

Step 4:

$\mathrm{H}_{5}$ : A linear combination of students' selfreported trait and state communication apprehension will be negatively correlated with students' affect and behavioral commitment.

Multiple-regression analysis was employed to test Hypothesis 5. Students' trait and state CA comprised the predictor set with students' affect and behavioral commitment as the single criterion variable. Hypothesis 5 was confirmed $(F=18.76$; $p<$ $.0001)$. Commonality analysis demonstrated that variance unique to students' PRCA was 2.45 percent and variance unique to state apprehension was 28.65 percent. Combined trait and state measures acted as suppressor variables, reducing explained variance by 2.35 percent (total $R^{2}=.2875$ ). The best interpretation for total variance explained in students' affect and behavioral commitment, then, was students' state apprehension.

\section{FIGURE 8}

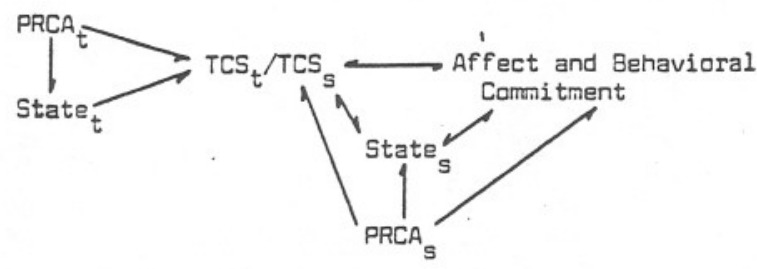


Step 5:

$\mathrm{H}_{6}$ : A linear combination of students' trait and state communication apprehension will significantly predict each of the following dimensions of students' perceptions of TCS:

$\mathrm{H}_{6 \mathrm{a}}$ : Assertiveness

$\mathrm{H}_{6 \mathrm{~b}}$ : Versatility

$\mathrm{H}_{6 \mathrm{c}}$ : Responsiveness

To test Hypothesis 6 (a, b, and c), a series of three multiple-regression analyses were employed with students' PRCA and state apprehension as predictors and students' perceptions of each dimension of TCS (i.e., assertiveness, versatility, and responsiveness) as separate criterion variables. Hypotheses $6_{\mathrm{a}}, 6_{\mathrm{b}}$, and $6_{\mathrm{c}}$ were supported. Students' trait and state $C A$ accounted for 8.54 percent of the variance in students' perceptions of assertiveness $(\mathrm{F}=4.34, \mathrm{p}<.01) ; 46$ percent of the variance in versatility $(F=40.14, p<.0001)$; and 43 percent of the varance in responsiveness $(F=34.78$, $\mathrm{p}<.0001$ ).

Commonality analysis indicated that for students' perception of teacher assertiveness $\left(R^{2}=\right.$ .0854 ), unique variance contributed by students' PRCA was .03 percent; students' state apprehension was 7.78 percent; and the combination of both PRCA and state apprehension was .73 percent of the total explained variance. Consequently, students' state apprehension was the most meaningful predictor of students' perceptions of their teacher's assertiveness.

For students' perceptions of versatility $\left(\mathrm{R}^{2}=\right.$ .4633), variance unique to PRCA was .01 percent; unique to state apprehension was 41.03 percent; and the combination of both PRCA and state apprehension contributed 5.29 percent of the total explained variance. Again, students' state apprehension was the most meaningful predictor of students' perceptions of their teacher's versatility.

For students' perceptions of responsiveness $\left(R^{2}=.4279\right)$, variance unique to PRCA was 1.33 percent; unique to state apprehension was 41.43 percent and the combination of both PRCA and state was .03 percent of the total explained variance. Like assertiveness and versatility, students' state apprehension was the most meaningful predictor of students 'perceptions of their teacher's responsiveness.
Consequently, Hypothesis 6 was supported with the interpretation that students' state apprehension was a more meaningful predictor of students' perceptions of their teacher's communication style than students' trait communication apprehension.

Research Question 3: Will students' perceptions of teacher assertiveness, versatility, and responsiveness significantly predict students' state apprehension?

Multiple-regression analysis was employed to answer Research Question 3. Students' perceptions of their teacher's assertiveness, versatility, and responsiveness served as predictors with students' state $\mathrm{CA}$ as the single criterion. Results indicated that students' perceptions of their teacher's communication style significantly predicted students' state apprehension $(F=29.41, p<.0001)$.

Commonality analysis indicated that while unique variance was differentially attributable to each variable, the primary predictors were a combination of versatility and responsiveness (.3238, total $R^{2}=.4896$ ). In response to Research Question 3 then, it appears that the combination of students' perceptions of their teacher's versatility and responsiveness were the most meaningful predictors of students' state apprehension (see Summary Table 2).

Research Question 4: Will the addition of students' trait and state CA be more predictive of students' affect and behavioral commitment than students' perceptions of TCS alone?

Multiple-regression analysis was employed to answer Research Question 4. Students' PRCA and state apprehension as well as students' perceptions of teacher assertiveness, versatility, and responsiveness served as predictors with students' affect and behavioral commitment as the single criterion variable. Results indicated that the predictor set significantly predicted students' affect and behavioral commitment $(F=13.61, p<.0001)$ and accounted for 43.05 percent of the total explained variance. However, when students' PRCA was entered first into the regression analysis, neither the sequential nor partial correlation was significantly related to students' affect and behavioral commitment. 
TABLE 2

Commonality Analysis Summary Table

Perceived Teacher Style as Predictor of Students' State Communication Apprehension

\begin{tabular}{|c|c|c|c|}
\hline \multirow[b]{2}{*}{ Unique and Common Effects } & \multicolumn{3}{|c|}{$\begin{array}{c}\text { Components in Perceived } \\
\text { Teacher Style }\end{array}$} \\
\hline & $\begin{array}{l}\text { Assert- } \\
\text { iveness }\end{array}$ & $\begin{array}{l}\text { Versa- } \\
\text { tility }\end{array}$ & $\begin{array}{l}\text { Respon- } \\
\text { siveness }\end{array}$ \\
\hline Unique to Assertiveness & .0022 & & \\
\hline Unique to Versatility & & .0576 & \\
\hline Unique to Responsiveness & & & .0231 \\
\hline $\begin{array}{c}\text { Common to Assertiveness } \\
\text { and Versatility }\end{array}$ & .0152 & .0152 & \\
\hline $\begin{array}{l}\text { Common to Assertiveness } \\
\text { and Responsiveness }\end{array}$ & .0011 & & .0011 \\
\hline $\begin{array}{l}\text { Common to Versatility } \\
\text { and Responsiveness }\end{array}$ & & .3238 & .3238 \\
\hline $\begin{array}{c}\text { Common to Assertiveness, } \\
\text { Versatility, and } \\
\text { Responsiveness }\end{array}$ & .0666 & .0666 & .0666 \\
\hline Totals & .0851 & .4632 & .4146 \\
\hline Squared Multiple Correlation: .4896 & & & \\
\hline
\end{tabular}

A second multiple-regression analysis was employed with students' PRCA omitted from the predictor set. Instead, students' perceptions of teacher assertiveness, versatility, and responsiveness as well as students' state CA served as predictors with students' affect and behavioral commitment as the single criterion variable. Results indicated that the new predictor set accounted for 41 percent of the total explained variance $(F=15.75, p<.001)$-a decrease of only 2 percent of explained variance when students' PRCA was omitted from the analysis.

Commonality analysis indicated that while unique variance was attributable to each variable $\left(\mathrm{R}^{2}=.4091\right.$; assertiveness $=.0462$; versatility $=$ .0107 ; responsiveness $=.0011$; and state apprehen- sion $=.0313$ ) and the combinations of variable sets (see Summary Table 3), a combination of all four predictor variables contributed substantially more explained variance in the criterion (.1083). In response to Research Question 4 then, it appears that the combination of students' state CA and students' perceptions of the teacher's communication style were the most meaningful predictors of students' affect and behavioral commitment.

\section{SUPPLEMENTARY ANALYSES}

In an effort to determine the significant predictor(s) of students' state apprehension in the classroom, the following additional analyses were employed. Pearson $r$ correlations demonstrated that 
TABLE 3

Commonality Analysis Summary Table

Perceived Teacher Style and Students' State Apprehension as Predictors of Affect and Behavioral Commitment

Unique \& Common Effects

Assertiveness

Versatility

Responsiveness

State

Unique to Assertiveness

.0462

Unique to Versatility

.0107

Unique to Responsiveness

.0011

Unique to State Apprehension

Common to Assertiveness and Versatility

$-.0088$

$-.0088$

Common to Assertiveness and Responsiveness

.0406

Common to Assertiveness and State

$-.0046$

$-.0046$

.0189

and Responsiveness

.0189

.0176

and State

.0176

.0039

Common to Responsiveness and State

(continued) 
TABLE 3 (Continued)

\begin{tabular}{|c|c|c|c|c|}
\hline Unique and Common Effects & Assertiveness & Versatility & Responsiveness & State \\
\hline $\begin{array}{l}\text { Common to Assertiveness, } \\
\text { Versatility, and } \\
\text { Responsiveness }\end{array}$ & .0374 & .0374 & .0374 & \\
\hline $\begin{array}{l}\text { Common to Assertiveness, } \\
\text { Versatility and State }\end{array}$ & -.0080 & -.0080 & & -.0080 \\
\hline $\begin{array}{l}\text { Common to Assertiveness, } \\
\text { Responsiveness, and } \\
\text { State }\end{array}$ & .0141 & & .0141 & .0141 \\
\hline $\begin{array}{l}\text { Common to Versatility, } \\
\text { Responsiveness, and } \\
\text { State }\end{array}$ & & .1004 & .1004 & .1004 \\
\hline \multicolumn{5}{|l|}{$\begin{array}{l}\text { Common to Assertiveness, } \\
\text { Versatility, Respon- } \\
\text { siveness, and State }\end{array}$} \\
\hline Totals & .2252 & .2765 & .3247 & .2630 \\
\hline Squared Multiple Correlation: & $: .4091$ & & & \\
\hline
\end{tabular}


none of the teacher variables (teachers' PRCA, state apprehension, or teachers' self-reported communication style) was significantly correlated with students' state apprehension. However, students' perceptions of their teacher's communication style were significantly correlated with students' state apprehension (assertiveness, $\mathrm{r}=-.29$, $\mathrm{p}<.01$; versatility, $\mathrm{r}=-.68, \mathrm{p}<.0001$; and responsiveness. $r=-.64, p<.0001)$. Further, commonality analyses referenced in Research Question 3 indicated that the combination of all three perceived teacher communication-style variables were significant predictors of students' state apprehension $\left(R^{2}=.49, F=29.41, p<.0001\right)$.

The model, however, suggests that students' state apprehension is additionally derived from students' trait communication apprehension. Pearson $r$ correlations indicated that students' state apprehension and PRCA were significantly correlated $(r=$ .35, $\mathrm{p}<.01$ ). By adding students' PRCA to the predictor set of students' perceived TCS, total explained variance of students' state may be significantly increased.

A multiple-regression analysis was employed with students' PRCA and students' perceptions of their teachers' assertiveness, versatility, and responsiveness as the predictors, and students' state apprehension as the single criterion variable. Results indicated that the new predictor set accounted for 54 percent of the total explained variance $(F=$ 26.7, $p<.0001$ ) - an increase of 5 percent of total explained variance for students' state apprehension.

Results of commonality analysis for students' state apprehension $\left(R^{2}=.5400\right)$ indicated that unique variance was differentially attributable to each variable as well as the various combinations of variable sets (see Summary Table 4). According to this analysis, the most meaningful predictors of students' state apprehension in the classroom were the combined predictors of students' perceptions of teacher versatility and responsiveness-accounting for 28.44 percent of the total explained variance.

A second supplementary analysis examined the relationships among teachers' PRCA, teacher and student perceptions of teacher assertiveness, and students' affect and behavioral commitment. Kearney-Knutson (1980) reported that teachers' and students ' perceptions of teacher communication style were found to have some association-at least for the assertiveness dimension of teacher communication style $(r=.27, p<.005)$. However, partial correlations demonstrated that teachers' PRCA is negatively correlated with students' perceptions of teachers' assertiveness $(r=-.27, p<$ .005). Given the identical correlations between teachers and students' perceptions of assertiveness when compared to teachers' PRCA and students' perceptions of assertiveness, it appears that students' perceptions of teachers ' assertiveness may be a function of the behaviors with which teachers engage that are directly attributable to teachers' trait communication apprehension. Further, students' perceptions of teacher assertiveness was associated with students' affect and behavioral commitment. Yet the relationship between teachers' PRCA and students' affect and behavioral commitment was nonsignificant ( $r=-.02$, nsd). When either teachers' trait or state was added to a regression model predicting affect and behavioral commitment, total explained variance was not increased (see data analyses referenced in Research Question 2). It appears then, that teachers' PRCA does not directly impact students' affect and behavioral commitment, but instead, is indirectly associated with that criterion based on teacher behaviors of assertiveness that students perceive.

\section{DISCUSSION}

The empirical model tested in this study examined the effects of teacher communication style-as perceived by either teachers or students-on students' affect and behavioral commitment in college classes. Additionally, the model posited a mediational function for teachers' and students' trait and state CA for perceptions of teacher style, affect, and behavioral commitment. The following illustration depicts these hypothesized relationships. The results of this investigation demonstrated that TCS, while a meaningful predictor of students' affect and behavioral commitment, relies on students' perceptions rather than teachers' self-assessments of their own teaching style.

Assertiveness. Teacher assertiveness, the first dimension of TCS, reflects perceptions of teacher control in the classroom. Students who perceived 
TABLE 4

Perceived Teacher Style and Students' PRCA as Predictors of Students' State Communication Apprehension

Unique \& Common Effects

Unique to PRCA

Unique to Assertiveness

Unique to Versatility

Unique to Responsiveness

Common to PRCA and Assertiveness

Common to PRCA and Versatility

Common to PRCA and Responsiveness

Common to Assertiveness and Versatility

Common to Assertiveness and Respansiveness

PRCA

Assertiveness.

Versat1lity

Responsiveness

.0504

.0048

.0347

$-.0026 \quad-.0026$

.0272

$-.0116$

$$
.0272
$$

.0142

.0142

$-.0017$

$-.0017$

Common to Versatility and Responsiveness

.2844

.2844

Common to PRCA, Assertiveness, and Versatility

.0010

.0010

.0010

Common to PRCA, Versatility, and Responsiveness 


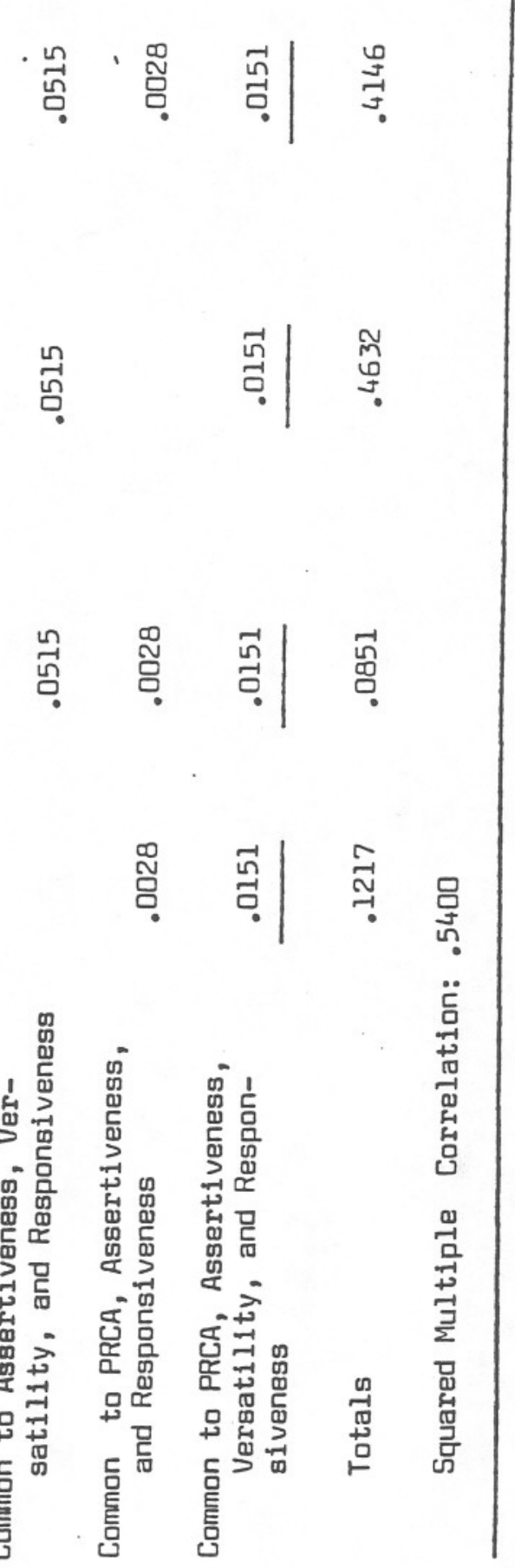

teachers as decisive, deliberate, challenging, and dynamic also reported greater affect and behavioral commitment toward the teacher, class, and subject content. Model II illustrates these interrelationships among critical variables relevant to the assertiveness dimension of teacher communication style with Pearson $r$ intercorrelations inserted. Where zeroes appear in the diagram, nonsignificant correlations were obtained.

These results further suggest that teachers 'trait $\mathrm{CA}\left(\mathrm{PRCA}_{t}\right)$, rather than state $\mathrm{CA}$, was a significant predictor of those perceptions of assertiveness. Teachers who were perceived highly assertive also self-reported low trait CA. Examination of the assertiveness construct reveals that assertiveness may be indicative of a type of state apprehension. Teachers high in assertiveness may engage in behaviors characteristic of the low-state CA. That is, highly assertive teachers may be perceived as avoiders of responsibility, indecisive, reserved, and uncommunicative. Similarly, low-trait CAs are approach-oriented in their communication encounters, while high-trait CA's engage in avoidance of real or potential communication situations (McCroskey, 1977).

The conclusion that dynamic, assertive teachers were well-liked by their students, and promoted greater affect and behavioral commitment toward the teacher and course is already well-supported in literature (Roberts \& Becker, 1976; Wyckoff, 1973; Deshpande, Webb, \& Marks, 1970; Ryans, 1960). However, the conjecture that highly challenging, aggressive teachers may simultaneously create anxiety toward communicating in the classroom was examined in this investigation as well. These results suggest that student perceptions of high teacher assertiveness were associated with lower students' state apprehension in the classroom. (Note: No causal relationship is asserted here or elsewhere in this study. One can only suggest associations.) Based on this investigation, teacher assertiveness-training may indeed promote positive student affect and behavioral commitment without correspondingly reducing students ${ }^{\circ}$ communicative involvement in the classroom.

Versatility. Versatility, the second dimension of TCS style, refers to perceived adaptiveness of the instructor to students' needs and characteristics. 


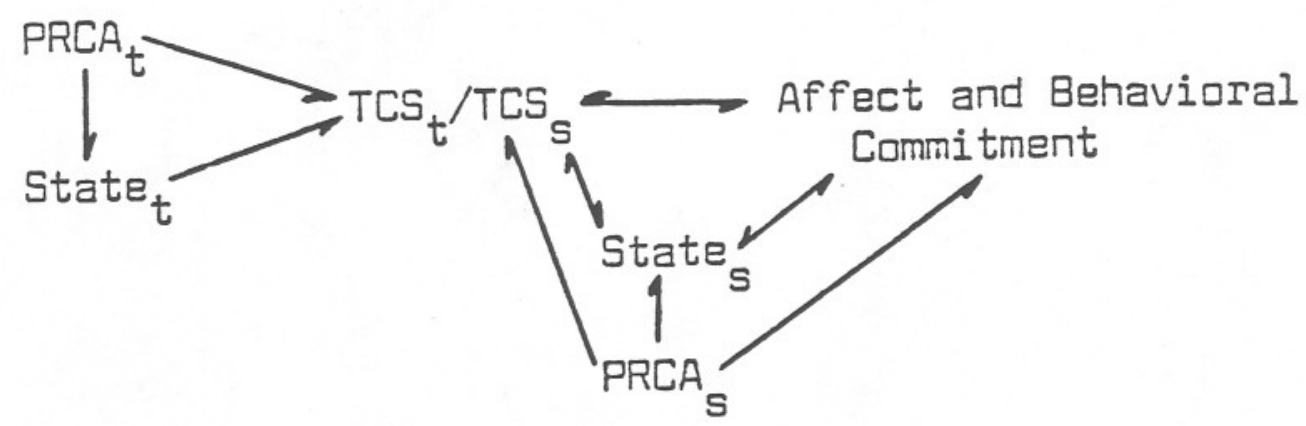

MODEL 1

Relationships Among Teacher Communication Style, Communication Apprehension, and Affect and Behavioral Commitment

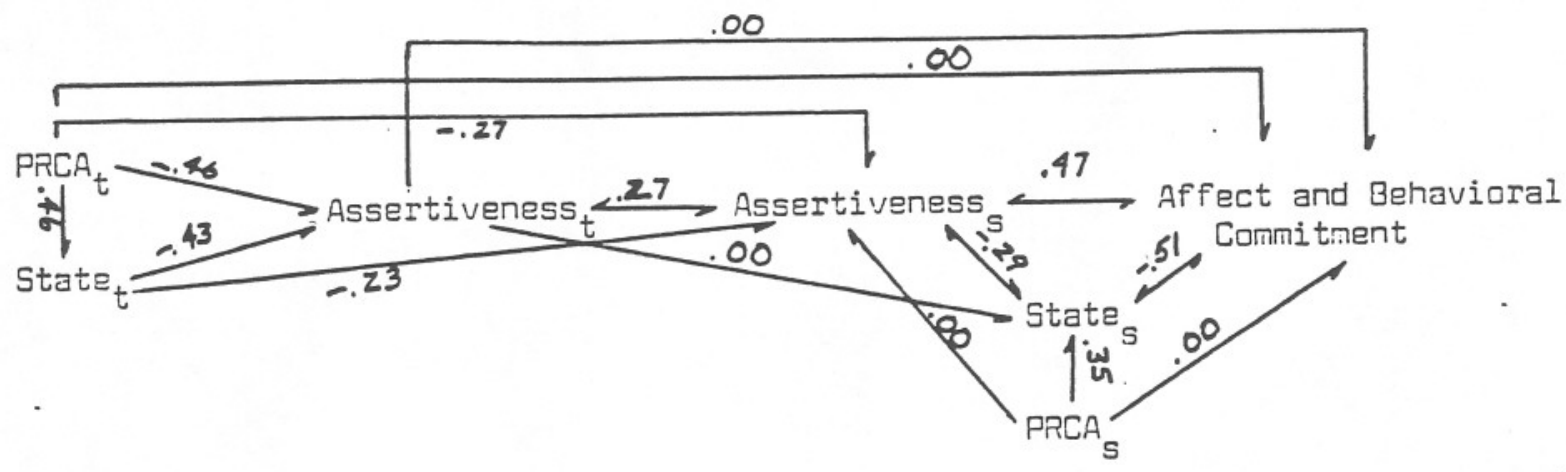

MODEL 2

Assertiveness Dimension of Teacher Communication Style

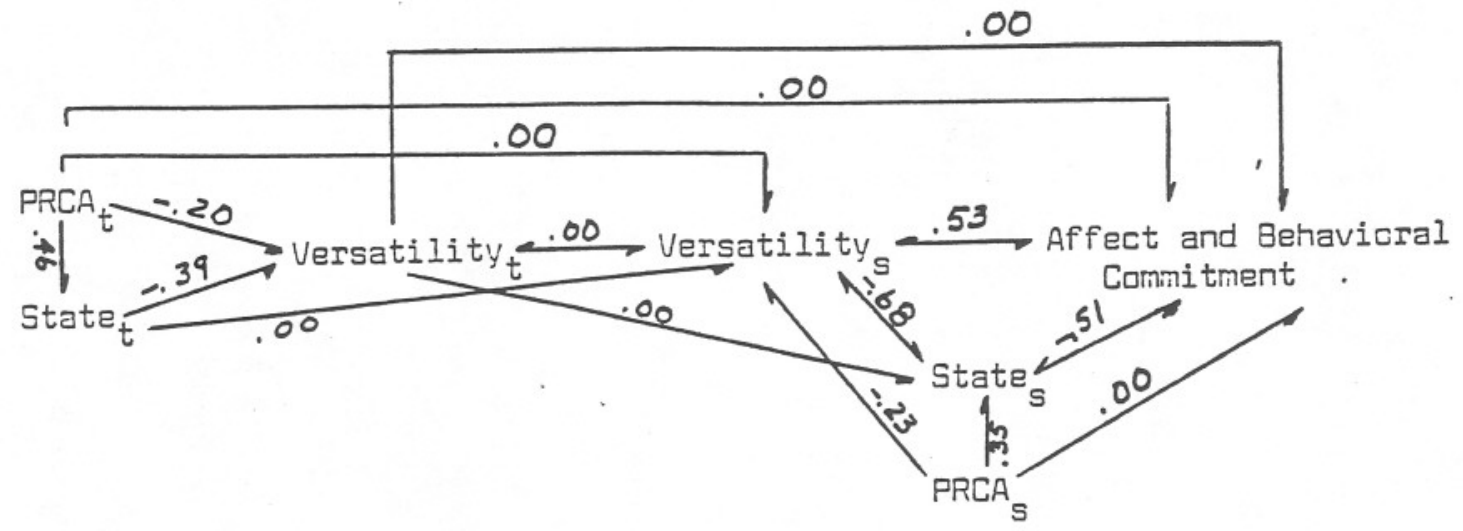

MODEL 3

Versatility Dimension of Teacher Communication Style 


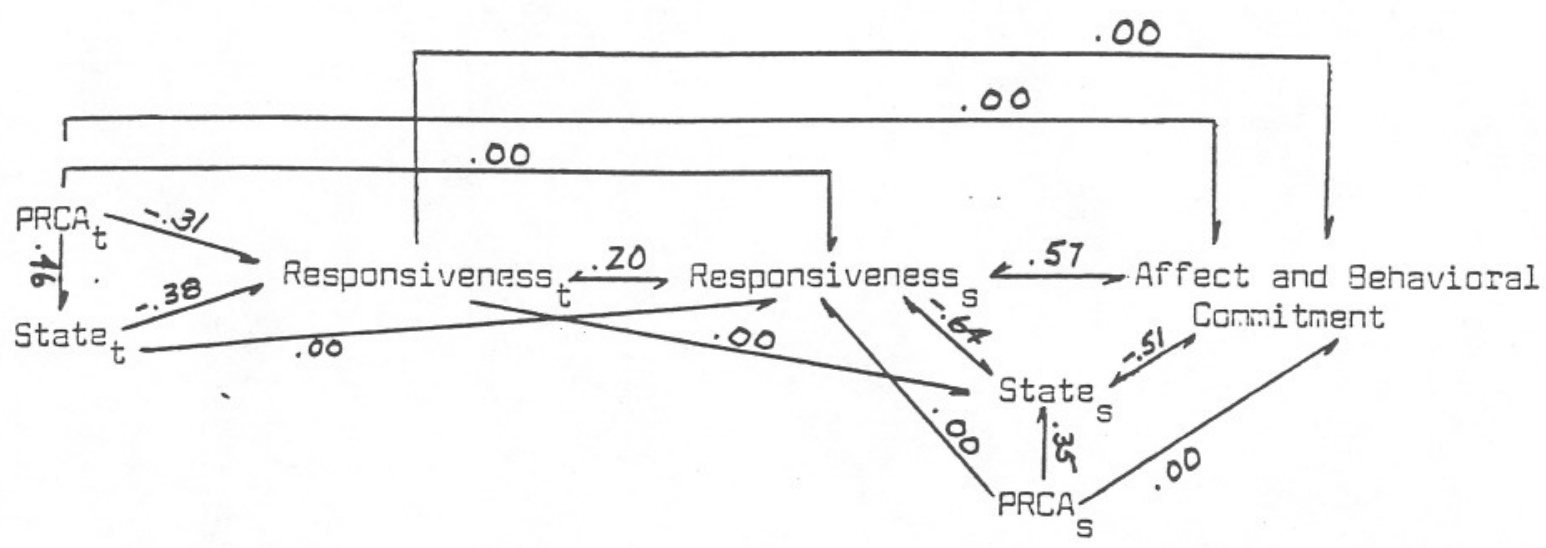

MODEL 4

Responsiveness Dimension of Teacher Communication Style

Students who perceived their teacher as encouraging student input, flexible, accommodating, and informal also self-reported greater affect and behavioral commitment toward the class, content, and instructor. Model III illustrates intercorrelations among those critical variables relevant to the versatility dimension of TCS.

While a direct relationship was reported between student-perceived teacher versatility and student affect and behavioral commitment, an indirect relationship was noted as well. Versatility was significantly related to students' state CA in the classroom. In turn, students' state CA was directly related to students' affect and behavioral commitment. These results suggest that not only do accommodating, flexible, adaptive, or versatile teaching styles predict greater student affect and behavioral commitment, but they may also serve to reduce students' fears of communicating in the classroom. Relaxed, approach-oriented communicators in the classroom tend to like the class and instructor, and they report higher effect and behavioral commitment as well.

Responsiveness. Responsiveness, the third dimension of TCS, refers to emotive, approachable, sensitive, and uninhibited teachers in the classroom. Like assertiveness and versatility, students who perceived their teachers as responsive also self-reported greater affect and behavioral commitment. Model IV illustrates significant intercorrelations among critical variables relevant to responsiveness.
Coupled with versatility, responsiveness also predicted an indirect relationship with students' affect and behavioral commitment. Those classes of students who reported lower levels of state apprehension about participating in classroom interactions with the instructor also perceived their teachers to be highly responsive. Correspondingly, low state apprehensive students reported greater affect and behavioral commitment. These results suggest that teachers perceived to be highly accessible, self-disclosive, and open in their interactions with students in class may also reduce students' anxieties about communication, while simultaneously promoting greater student affect and behavioral commitment.

However, the results indicated also that students' trait CA was a predictor of their own state apprehension. These results do not imply that teacher behaviors in the classroom are insensitive or irrelevant to students' potential willingness to participate in classroom interactions. Instead, this investigation suggests that students' perceptions of teacher versatility and responsiveness were more meaningful predictors of students' state apprehension in the classroom than students' level of trait CA. Consequently, teachers perceived as highly versatile and responsive may enhance student participation by reducing students' state apprehensionregardless of students' trait CA level.

The obvious benefit for the teacher in reducing students' state apprehension may be the corresponding increase in student feedback to instruc- 
tion. Student feedback is a potential source of peer-teaching and modeling. Feedback also serves to promote fidelity of communication in the instructional process. Finally, earlier investigations reported that students were perceived differentially by teachers as a function of student levels of trait $\mathrm{CA}$. Teachers predicted higher achievement levels for the more talkative student (McCroskey \& Daly, 1976) and expected low CA students to establish better interpersonal relationships with others; to enjoy greater success in their careers; and to perform better in educational endeavors than highly apprehensive students (Smythe \& Powers, 1978). The results of these studies suggest that reduced $\mathrm{CA}$ in the classroom and, correspondingly, increased student participation and involvement may lead to more positive teacher perceptions and expectancies for students' performance and achievement in class.

Finally, previous research reported that students' trait CA predicted attitudes toward school in general (Hurt \& Preiss, 1978). Perhaps trait CA is negatively associated with generalized or traitlike attitudes toward school, but this investigation found no such relationship for specific attitudes toward a class. Instead, students' state CA predicted students' affect and behavioral commitment. Future research designed to investigate students' affect and behavioral commitment in instruction should control for students' state CA for increased precision in prediction and interpretation. (See KearneyKnutson, 1979, for a detailed critical assessment of selection procedures, internal and external validity, measures employed, and further suggestions for future research.)

\section{NOTE}

Special thanks to those who offered guidance in this research endeavor: Lawrence R. Wheeless and Michael D. Scott of West Virginia University; and Lawrence J. Chase of California State University at Sacramento.

\section{REFERENCES}

ANDERSEN. J. Perceptions of immediacy and communication style as altered by communication apprehension level. Paper presented to the annual meeting of the Western Speech Communication Association, Los Angeles, 1979a.

ANDERSEN, J. The relationship between teacher immediacy and teacher effectiveness. In D. Nimmo, (Ed.), Communi- cation Yearbook 3. New Brunswick. N. J.: TransactionInternational Communication Association. 1979b.

BRANAN, J.M. Negative human interaction. Journal of Counseling Psychology, 1972, 19, 81.82

BRUNER. J.S., GOODNOW. J.J., \& AUSTIN, G.A. A study. of thinking. New York: John Wiley \& Sons, 1956.

BUCHHOLZ, S. . LASHBROOK, W.B., \& WENBURG, J.R. Toward the measurement and processing of social style. Paper presented at the annual meeting of the International Communication Association. Chicago, 1975.

COHEN. J. Statistical power analysis for the behavioral sciences. New York: Academic Press, 1977.

COMBS, A.W.Individual behavior. New York: Harper. 1959.

COREY, S.M. Definition of instructional design. In P.C. Lange. (Ed.), Programmed Instruction: NSSE 66th Yearbook, Part Il. Chicago: University of Chicago Press, 1967.

DAVIES. G.F. \& SCOTT. M.D. Communication apprehension, intelligence, and achievement among secondary school students. In B.D. Ruben, (Ed.), Communication Yearbook 2. New Brunswick. N. J.: Transaction-International Communication Association. 1978.

DAVIES, I.K. Competency based learning: technology, management, and design. New York: McGraw-Hill, 1973.

DESHPANDE. A.S., WEBB. S.C., \& MARKS, E. Students' perceptions of engineering instructor behaviors and their relationships to the evaluation of instructors and courses. American Educational Research Journal, 1970, 7, 289-305.

ELLIOT. S. The relationship between background, attitude and competence homophily and cognitive, affective and behav. ioral learning. In D. Nimmo, (Ed.), Communication Yearbook 3. New Brunswick. N. J.: Transaction-International Communication Association. 1979.

FURTH. H.G. Piaget and knowledge: theoretical foundations. Englewood Cliffs, N. J.: Prentice-Hall, Inc., 1969.

GINSBURG. H. \& OPPER. S. Piaget's theorn of intellectual development: an introduction. Englewood Cliffs, N. J.: Prentice-Hall. 1969.

HOLLAND. J.G., SOLOMON, D., DORAN. J., \& FREZZA. D.A. The analysis of behavior in planning instruction. Reading, Mass.: Addison-Wesley, 1976.

HURT. H.T. \& PREISS. R Silence isn't necessarily golden: communication apprehension. desired social choice, and academic success among middle-school students. Human Communication Research, 1978, 4, 315-27.

KEARNEY-KNUTSON. P.K. Relationships among teacher communication style, trait and state communication apprehension, and teacher effectiveness. Unpublished doctoral dissertation. West Virginia University, 1979.

KEARNEY-KNUTSON, P.K. Perceptual discrepancies in teacher communication style: both sides now. Paper presented at the annual meeting of the Western Speech Communication Association. Portland, Oregon. 1980.

KELLER, F.S. \& SHERMAN, J.G. The Keller Plan handbook. Menlo Park, Calif.: W.A. Benjamin Co., 1974.

KEMP. J.E. Instructional design: a plan for unit and course development. Belmont. Calif.: Fearon Publishers. 1971.

LAMB, D.H. Speech anxiety: Towards a theoretical conceptualization and preliminary scale development. Speech Monographs. 1972, 39. 62-67.

McCROSKEY, J.C. Oral communication apprehension: a summary of recent theory and research. Human Communication Research, 1977, 4, 78-96.

McCROSKEY. J.C. Measures of communication bound anxiety. Speech Monographs, 1970, 37. 269-77. 
MCCROSKEY. J.C. \& ANDERSEN, J.F. The relationship between communication apprehension and academic achievement among college students. Human Communication Research, 1976, 3. 73-81.

MCCROSKEY, J.C. \& DALY, J.A. Teacher expectations of the communication apprehensive child. Human Communication Research. 1976, 3, 67-72.

McPHEE. R.D. \& SEIBOLD. D.R. Rationale. procedures, and applications for decomposition of explained variance in multiple regression analyses. Communication Research, 1979. 6. 345-84.

MERRILL. D. Reference survey profile. Denver: Personal Predictions and Research. Inc. 1974

NORTON. R.W. Foundation of a communicator style construct. Human Communication Research. 1978, 4, 99-112.

NORTON. R.W. Teacher effectiveness as a function of communicator style. In B.R. Ruben, (Ed.). Communication Yearbook I. New Brunswick, N. J.: TransactionInternational Communication Association. 1977.

RICHMOND. V.P. The relationship between trait and state communication apprehension and interpersonal perceptions during acquaintance stages. Human Communication Research, 1978, 4. 338-49.

ROBERTS. C.L. \& BECKER, S.L. Communication and teaching effectiveness in industrial education. American Educational Research Journal, 1976, 13, 181-97.

ROGERS. C.R. Freedom to learn. Columbus, Ohio: Charles E. Merrill. 1969.

RYANS. D.G. Characteristics of teachers: their description, comparison, and appraisal. Manasha, Wis.: George Banta Co.. Inc.. 1960.

SCOTT, M.D. \& WHEELESS, L.R. Toward a reconceptuali- zation of the relationship between communication apprehension and learning: a critical review. Paper presented at the annual meeting of the International Communication Association. Chicago. 1978.

SCOTT. M.D..'YATES, M.P., \& WHEELESS, L.R. An exploratory investigation of the effects of communication apprehension in alternative systems of instruction. Paper presented at the annual meeting of the International Communication Association. Chicago, 1975.

SEIBOLD, D.R. \& McPHEE. R.D. Commonality analysis: a method for decomposing explained variance in multiple regression analysis. Human Communication Research, 1979. 5. 355-365.

SKINNER, B.F. The technology of teaching. Englewood Cliffs, N. J.: Prentice-Hall, 1968.

SMYTHE. M.J. \& POWERS, W.G. When Galatea is apprehensive: the effect of communication apprehension on teacher expectations. In B.D. Ruben, (Ed.), Communication Year. book 2. New Brunswick. N. J.: Transaction-International Communication Association. 1978.

SNELBECKER, G.E. Learning theon: instructional theorv, and psychoeducational design. New York: McGraw-Hill Book Co.. 1974.

SPIELBERGER, C.D. (Ed.) Anxiety and behavior. New York: Academic Press, 1966.

VARGAS, J.S. Behavioral psychology for teachers. New York: Harper \& Row, 1977.

WITTICH, W.A. \& SCHULLER, C.F. Instructional technology: its nature and use. New York: Harper \& Row, 1973.

WYCKOFF, W.L. The effects of stimulus variation on leaming from lecture. Journal of Experimental Education. 1973, 41. 85-90. 